\title{
Estimating the Optimal Land Management Scale of Big Grain Production Households and Comprehensive Family Farms Based on the Decision Graph
}

\author{
Fang Luo ${ }^{1, ~ *, ~ M i a o ~ T i a n ~}{ }^{2}$, Qingli Xia ${ }^{3}$, Dan $X u^{1}$, Caihong Sun ${ }^{1}$ \\ ${ }^{1}$ School of Commerce, Huanggang Normal University, Huanggang City, China \\ ${ }^{2}$ Economics and Management College, Zhaoqing University, Zhaoqing City, China \\ ${ }^{3}$ Teaching Affairs Department, Huanggang Normal University, Huanggang City, China
}

\section{Email address:}

luofang68@qq.com (Fang Luo), tianmiaoqq@yahoo.com.cn (Miao Tian), xiaqingli@yeah.net (Qingli Xia), 290651528@qq.com (Dan Xu), suncaihong@163.com (Caihong Sun)

${ }^{*}$ Corresponding author

\section{To cite this article:}

Fang Luo, Miao Tian, Qingli Xia, Dan Xu, Caihong Sun. Estimating the Optimal Land Management Scale of Big Grain Production Households and Comprehensive Family Farms Based on the Decision Graph. International Journal of Economics, Finance and Management Sciences. Vol. 5, No. 6, 2017, pp. 312-320. doi: 10.11648/j.ijefm.20170506.16

Received: November 3, 2017; Accepted: November 9, 2017; Published: December 28, 2017

\begin{abstract}
Farmland scale management can bring large scale benefits to producers, promote labour productivity and increase farmers' income. However, excessive concentration of farmland also has a few shortcomings, such as decreases in intensive farming, farmland productivity, and employment efficiency. Identifying the optimal land management scale is an effective means to improve agricultural production efficiency. Regression analysis is used to estimate the optimal land management scale under current productivity in China. Further, a decision graph has been drawn, which shows that the scale of big grain production households and comprehensive family farms is generally less than the optimal level, and an inverse relationship exists between farm size and productivity. Lastly, the suggestions that scattered land should be concentrated in the hands of big grain production households and family farms, and that land-lost farmers should work in their local agricultural industry, participating in the profit from land production are made.
\end{abstract}

Keywords: Big Grain Production Household, Comprehensive Family Farm, Optimal Land Management Scale, Decision Graph

\section{Introduction}

In the context of the household contract responsibility system resulting in land fragmentation and low agricultural comparative gains, the first document of China's central government in 2013 put forward that rural land contracted management rights should lead to orderly transfer; professional investors, family farms and farmers cooperatives should be encouraged to invest in contracted land; and diversified moderate scale management should be developed. Hence, a new round of land circulation climax was triggered, and a new-style of agricultural management subjects, such as big grain production households and family farms, became prevalent. Representing conformity of production relations to the state of productive forces at a particular time [1], big grain production households and family farms are innovative in their approach to agricultural production, including useful exploration of land operational mechanisms, and they show a bold attempt to cultivate new-style agricultural operation subjects, which not only stabilizes food production but also promotes rural labour non-agriculture transfer. According to the China Department of Agriculture data, there are presently 737.9 thousand big grain production households (including grain cooperatives) around the country, covering 13.7 million $\mathrm{hm}^{2}$ of land and producing 123.2 billion $\mathrm{kg}$ of grain, which accounts for $20.9 \%$ of the total output. This finding shows that big grain production households are important in China's grain production. In addition, $79.1 \%$ of food is produced by 
scattered farmers and family farms, which shows that family farms should not be ignored. Due to the constraints of revenue instability, flawed competition and contracts, the development of big grain production households has been limited. Family farms can not only motivate family members but also conduct enterprise operations, which is a new-style of production and management that combines the two advantages of family production and enterprise operation. Hence, by complementing each other, family farms and big grain production households have become China's main management modes [2].

While land is transferred between farmers or is concentrated by big farmers, following the law of the factor market, the agricultural subjects of production and operation voluntarily transacting can realize efficient resource allocation. However, merely by visiting several successful cases of scale management, a few local government officials have followed suit and started rural land scale management reforms. These officials did not consider local practice and did not create a phased implementation plan or supporting programmes. Thus, in the social practice of farmland scale management, a few rural producers obtain economies of scale, but a good number of producers do not. Two opposing practice results have led to two opposing viewpoints in academia, i.e., "inverse relationship" and "increasing returns to scale". Are "inverse relationship" and "increasing returns to scale" irreconcilable? What are the reasons for their emergence? What is their watershed? Focusing on those problems, and based on survey data of 211 big grain production households and 257 comprehensive family farms, regression was used analysis to estimate their optimal land management scale from the perspective of maximizing the use of labour and land, respectively. A decision graph of land scale management was drawn further. It is of great significance in enabling the big grain production households and comprehensive family farms to realize the goal of revenue maximization and raising the utilization efficiency of existing agricultural capital and technologies.

\section{Review of Related Literatures}

The related literatures are mainly divided into two types as follows: optimal land management scale and tests of the inverse relationship (IR) between farm size and productivity.

Scholars have studied the scale management of big grain production households and family farms, but very few have paid attention to comprehensive family farms. The extant literatures are mostly field survey and empirical analysis. The main methods used are the Heckman two-stage model, interpretation structure model [3], convergence analysis [4], DEA-bootstrapped truncated regression [5], and ordered Probit model [6]. The results found that the factors affecting farmland management scale include the following: (i) superficial factors, such as rural household borrowing power, in which informal lending systems and formal financial institution loans have a significant positive influence on land size [5], (ii) middle-level factors, such as family resource endowment, in which capital and the number of labourers have a significant negative influence [7], and (iii) deep factors, such as other farmers' management decisions, and the family's attitude and policy incentives [8]. The main estimating methods of moderate scale are the direct estimating method, the grouped comparison method, the comprehensive evaluation method, and the production function analysis method [9]. A farm operated by a farming family and, at most, an employee is the most effective agricultural production unit [10]. Different regions or the same region's different big grain production households and family farms result in different optimal land management scales because resource endowment, technological levels and crop varieties are different. Under current productivity levels, the maximum values of wheat-maise and wheat-rice net yields per unit area of big grain production households are approximately $17.1 \mathrm{hm}^{2}$ and $16.4 \mathrm{hm}^{2}$, respectively [1]. A family farm of approximately $6.66 \mathrm{hm}^{2}$ has advantages in cost, risk, land transfer, economic benefits, ecological benefits and management [11]. Generally, the appropriate farm size of a big grain production household is from 2.0 to $3.3 \mathrm{hm}^{2}$ in South China, and $6.7 \mathrm{hm}^{2}$ in North China [12]. Scholars have also put forward instructive measurements, including establishing an early warning system of risk monitoring at the grain production scale [3], increasing the bargaining power of farmers [13], increasing farmers' ability to access advanced technologies [14], providing access to credit and irrigation, and promoting a degree of specialisation in rice production [5].

According to the results, the IR testing may be divided into two categories as follows: (i) supporting the IR. In India, for the two major agricultural seasons, kharif and rabi, and for both the seasons pooled together, Gaurav and Mishra's findings suggested the existence of an inverse relationship, even when they treated factors such as household types, social groups, agro-climatic zones and agricultural seasons as fixed effects [15]. The result was also robust in correcting for selection bias. In Latvia, large farm cows had higher productivity in one productive day and in one life day [16]. For Uganda's self-reported land size information complemented by plot measurements collected using global position system (GPS) devices, Carletto et al. strengthened an evidence in support of the existence of the IR [17]. In addition, (ii) not supporting the IR, either partially or completely. Labour market imperfections are the driving force behind the inverse relationships in Nicaragua and Rwanda [18], [19]. Land yields increased with plot size both by season and over the year in China [20]. Few scholars have focused on the decision graph of a farmland scale management, except $\mathrm{Ni}$ and $\mathrm{Cai}$, who used farmer's panel data and quantitatively analysed land moderate scale management [21].

In conclusion, the related research of the optimal farmland scale and productivity is fruitful, but there are some shortcomings, including the following: (i) the extant literatures are almost empirical analysis based on field survey and lacks related theoretical research. The mechanism of the 
land transfer motive of big grain production households, the upper and lower limit threshold determination of scale management, the policy's guiding role, the support effect of socialised services, and the influence of the characteristics of a big grain production household need to be studied. (ii) Comprehensive family farms deserve special focus; they are a general rural production organised form but are usually ignored. There are a few problems that have to be urgently resolved. For example, how do the operation modes, i.e., planting, breeding, leisure and travel, combine together to realise multiple goals, such as increasing agricultural output and farmers' income, while preserving the ecological environment? (iii) The policy proposals for improving the government's function and ensuring new-style agricultural management subjects ordered development almost remain at the talking stage, lacking operable and prospective top system design schemes and phased implementation plans. (iv) Research on the farmland scale management decision graph is limited. This method provides a new means to solve the problem of farmland scale optimisation. We have attempted to enrich this research area. The innovative point of our findings is that farm productivity monotonously decreases with size rather than initially decreasing and then increases when farm size reaches a certain scale, which is put forward by the extant literature [21].

\section{Theoretical Method, Model Selection and Data Sources}

\subsection{Basic Concept Definition}

The object of this research is the optimal farmland management scale. First, however, it is necessary to clarify three concepts: big grain production households, family farms and comprehensive family farms. A big grain production household is a natural person, a legal person, a specialised cooperative organisation or other organisation that is of a certain scale, grows at least one food crop, cultivates regularly, is managed as a whole, operates independently and is held responsible for profit and loss [22]. The family farm is a new-style agricultural management subject that engages in agriculturally scaled, intensive and commercial operations. The main labour force of the family farm is its members, and agricultural income is the important source of revenue [23]. The comprehensive family farm is a family farm with two or more management modes, such as planting, breeding and the other characteristic operations [21]. Thus, there is an intersection of the big grain production household and the family farm. For example, the family farm that only engages in growing food is also a big grain production household. Because the big grain production household only has one management mode, i.e., planting, and the comprehensive family farm has at least two management modes, such as planting-breeding, and planting-leisure agriculture, it is clear that there is a thin line between the big grain production household and the comprehensive family farm.

\subsection{Estimation Method and Data Resources}

The optimal land management scale was focused on when two agricultural core factors, i.e., labour and land, are maximally utilised, respectively. The independent variable $(X)$ is grain area, and the dependent variable $(Y)$ is family revenue per labour and grain yield per hectare, respectively. For labour endowment, with grain area increasing, family revenue per labour increases [24], but the incremental rate diminishes. After reaching a maximum, the revenue per labour decreases with the area, which is caused by the diminishing marginal return of labour [21]. Thus, the family revenue per labour takes the form of a quadratic function to represent its change rule. For land endowment, eliminating the impact of institutions, technological progress, etc., it is confirmed that grain yield per hectare decreases with farm size worldwide [15], [16], which is the famous Inverse Relationship (IR). With farm size continuously increasing, grain yield per hectare decreases at a diminishing rate. After reaching a minimum, grain yield per hectare increases [21]. Thus, grain yield per hectare takes the form of a quadratic function to represent its change rule. Above all, the functional expression of the family revenue per labour or the grain yield per hectare $(Y)$ and the grain area $(X)$ is $Y=a X^{2}+b X+c$, in which $a, b$ and $c$ are constant, and estimated by a regression model. Then, according to the significance of the estimated $a$, we determine whether an extreme value exists. If so, the first order condition of the function is used to obtain the optimal land management scale as follows:

$$
X_{0}=-\frac{b}{2 a}
$$

and the extreme value as follows:

$$
Y_{0}=\frac{4 a c-b^{2}}{4 a}
$$

\subsection{Model Setting and Variable Selection}

\subsubsection{The Big Grain Production Household Model}

In China, the key point of building modern agriculture is grain production, and a challenge is scale management. The big grain production household is an integrative product of planted grain adapting to specialized production, cooperative management and socialized service [25]. The optimal land management scale of the big grain production household is a focus of concern for producers, government and scholars. The grain yield per labour $(G Y P L)$ is taken as the dependent variable. Considered the periodicity of grain planting, the grain yield per labour is defined as the grain yield of labour per year, whose unit is a thousand $\mathrm{kg} /$ person-year. In addition, the per capita grain yield regression analysis is chosen as a theoretical comparison, whose dependent variable is per capita grain yield ( $P C G Y$ ). While the manager of the big grain production household makes decisions, he usually 
expects that influence on the family living level. Thus, $P C G Y$ means exactly the per capita grain yield of his household, whose unit is thousand $\mathrm{kg} /$ person-year. The established equation of regression analysis is as follows:

$$
\begin{aligned}
\text { GYPL }_{\mathrm{i}} & \left(\mathrm{PCGY}_{\mathrm{i}}\right)=\alpha_{0}+\alpha_{1} \mathrm{AREA}_{\mathrm{i}}+\alpha_{2} \text { AREA }_{i}^{2}+\alpha_{3} \text { EDU }_{\mathrm{i}} \\
& +\alpha_{4} \mathrm{NOL}_{\mathrm{i}}+\alpha_{5} \mathrm{FAC}_{\mathrm{i}}+\alpha_{6} \mathrm{TER}_{\mathrm{i}}+\alpha_{7} \mathrm{REG}_{\mathrm{i}} \\
& +\alpha_{8} \mathrm{FMSS}_{\mathrm{i}}+\alpha_{9} \mathrm{IRR}_{\mathrm{i}}+\mu_{\mathrm{i}}
\end{aligned}
$$

in which $i$ represents the $i$ th observation, $\alpha_{0}-\alpha_{9}$ are the parameters to be estimated, $A R E A$ is grain area whose unit is $\mathrm{hm}^{2}, A R E A^{2}$ is the square of $A R E A, E D U$ is the education years of the manager, $N O L$ is the number of labourers who engage in grain production and operation (including employees), FAC represents whether funds have been accumulated by a big grain production household (FAC having a value of 1 for having accumulated funds, otherwise, a value of 0 ), TER represents terrain (mountainous region, hills and plain ${ }^{1}$ have values of 1,2 and 3, respectively.), $R E G$ represents region ( $R E G$ has a value of 1 for northeast China, otherwise, a value of 0 ), FMSS represents whether the big grain production household has bought medium- or large-sized farm machinery or whether he can conveniently buy the related socialised services (FMSS having a value of 1 for having bought farm machinery or convenient buying socialised services, otherwise, a value of 0$), I R R$ represents the state of the irrigation facilities (IRR having a value of 1 for intact irrigation facilities, otherwise, a value of 0 ), and $\mu_{i}$ is an error term.

With grain area increasing, scale benefit promotes the grain yield per labour (or the per capita grain yield) [24], but growth rate decreases [21]. Thus, the expected sign of Area is positive and that of $A R E A^{2}$ is negative. While the manager of the big grain production household makes production decisions, his education level plays a decisive role in seizing opportunities and avoiding risks [26], therefore the expected sign of $E D U$ is positive. The number of labourers increasing promotes the degree of intensive farming, thus the expected sign of $N O L$ is positive. Obtaining a loan from a bank takes a long time and the procedure is complex. It is also necessary to make connections. The interest rate of funding outside the banking system is high, generally approximately $12 \%$, and even as high as $36 \%$ [22]. If the big grain production household has accumulated funds, it benefits investment in planting, so the expected sign of $F A C$ is positive. For growing food, a plain is better than hills, and hills are better than mountainous regions, thus the expected sign of TER is positive. Having bought medium- or large-sized farm machinery, or convenient buying related socialized services, reflects a higher degree of mechanization that represents agricultural science and a modern development level, thus the expected sign of FMSS is positive. Irrigation facilities are essential for agricultural production. Intact irrigation facilities are a necessary condition for both grain yield and farmers' income increasing; thus, the expected sign of IRR is positive.

1 The surveyed region only involves those three landforms.

\subsubsection{The Comprehensive Family Farm Model}

Under the precondition that both the factor market and the production market have been sufficiently developed, as a rational economic man, the farmer pursues the goal of maximizing his agricultural income. The comprehensive family farm has a combination of planting, breeding or other characteristic management modes, which is beneficial in realising both labour endowment and land endowment maximum utilization [27]. The agricultural income per labour $(A I P L)$ is taken as the dependent variable. Considered the periodicity of agricultural production, agricultural income per labour is defined as the agricultural production income of a labour year, whose unit is a thousand $\mathrm{RMB}$ /person-year. In addition, the per capita agricultural income regression is chosen as a theoretical comparison, whose dependent variable is per capita agricultural income $(P C A I)$. The unit of per capita agricultural income is a thousand $\mathrm{RMB} /$ person-year. While the farmer makes decisions, he usually considers whether the family can make a living on the income or improve the quality of their lives. The established equation of regression analysis is as follows:

$$
\begin{gathered}
\text { AIPL }_{\mathrm{i}}\left(\mathrm{PCAI}_{\mathrm{i}}\right)=\beta_{0}+\beta_{1} \mathrm{AREA}_{\mathrm{i}}+\beta_{2} \text { AREA }_{i}^{2}+\beta_{3} \mathrm{EDU}_{\mathrm{i}} \\
+\beta_{4} \mathrm{NOL}_{\mathrm{i}}+\beta_{5} \mathrm{FAC}_{\mathrm{i}}+\beta_{6} \mathrm{RMMFI}_{\mathrm{i}}+\beta_{7} \mathrm{TER}_{\mathrm{i}} \\
+\beta_{8} \mathrm{REG}_{\mathrm{i}}+\beta_{9} \mathrm{FMSS}_{\mathrm{i}}+\beta_{10} \mathrm{IRR}_{\mathrm{i}}+v_{\mathrm{i}},
\end{gathered}
$$

in which $\beta_{0}-\beta_{10}$ are the parameters to be estimated, Area is the management land area whose unit is $\mathrm{hm}^{2}$ (including arable land, pond, woodland, etc.), RMMFI is the ratio between a farmer's potential migrant money and his real farming income, and $v_{i}$ is an error term. The variable, RMMFI, represents the opportunity cost of the farmer. The larger the opportunity cost, the less the farmer feels at ease engaging in agricultural production and operation, and this will impact agricultural income. Hence, the expected sign of $R M M F I$ is negative. The explanations and the sign predictions of the other letters and variables are similar to regression Eq. (3) (previously presented), noticing that a small detailed description should be changed.

\subsubsection{The Inverse Relationship Testing Model}

The aforementioned discussions of both the big grain production household and the comprehensive family farm are based on the maximum utilisation of labour endowment. Similarly, they can also be analysed from a land endowment perspective, thus we will test the inverse relationship between grain yield per hectare and grain area for the big grain production household and the comprehensive family farm, respectively, in which the comprehensive family farm is only considered for food growth activities. In addition, we also fit in the aggregated data of the big grain production households and the comprehensive family farms to test the IR. The established equation of regression analysis is as follows:

$$
\begin{aligned}
& \text { GYPU }_{\mathrm{i}}=\gamma_{0}+\gamma_{1} \text { AREA }_{\mathrm{i}}+\gamma_{2} \text { AREA }_{i}^{2}+\gamma_{3} \text { EDU }_{\mathrm{i}} \\
& \quad+\gamma_{4} \mathrm{NOL}_{\mathrm{i}}+\gamma_{5} \mathrm{FAC}_{\mathrm{i}}+\gamma_{6} \mathrm{TER}_{\mathrm{i}}+\gamma_{7} \mathrm{REG}_{\mathrm{i}} \\
& \quad+\gamma_{8} \mathrm{FMSS}_{\mathrm{i}}+\gamma_{9} \mathrm{IRR}_{\mathrm{i}}+\varepsilon_{\mathrm{i}}
\end{aligned}
$$


in which $\gamma_{0^{-}} \gamma_{9}$ are the parameters to be estimated, GYPU is grain yield per unit whose unit is thousand $\mathrm{kg} / \mathrm{hm}^{2}$, Area is the grain area whose unit is $\mathrm{hm}^{2}$, and $\varepsilon_{i}$ is an error term. With a grain area increase, the degree of intensive farming and the grain yield per unit decrease [15]. Thus, the expected sign of $A R E A$ is negative. Although arable land cannot be intensively farmed, scale management may bring scale benefits. Hence, the grain yield per unit decreases at a diminishing rate, and the expected sign of Area $^{2}$ is positive. Explanations and sign predictions of the other letters and variables are previously described.

\subsection{Data Sources and Descriptive Statistics}

In August 2017, we used "Questionnaire Star", the platform of survey-test-vote to release the questionnaire of farmland management scale, agricultural labour input and revenue. 468 valid questionnaires were received, in which 211 copies are from the big grain production households and 257 copies are from the comprehensive family farms. The respondents came from 35 cities in 18 States/Provinces in China, such as Hubei, Hunan, Anhui, Henan, Shandong, Liaoning, and others.

The explanations and the descriptive statistics of the variables in Eq. (3)-Eq. (5) are shown in Table 1.

Table 1. Variable definitions and descriptive statistics

\begin{tabular}{|c|c|c|c|c|}
\hline Variables & Definitions & Mean & Std. Dev. & Sig. Pred. \\
\hline GYPL & Grain yield per labour & 17.185 & 20.041 & \\
\hline$P C G Y$ & Per capita grain yield & 19.302 & 55.029 & \\
\hline$A I P L$ & Agricultural income per labour & 79.485 & 33.137 & \\
\hline$P C A I$ & Per capita agricultural income & 89.412 & 49.034 & \\
\hline$G Y P U$ & Grain yield per unit & 14.776 & 1.906 & \\
\hline$A R E A$ & Farmland area & $9.482 / 6.295$ & $26.235 / 12.757$ &,,$++-^{\#}$ \\
\hline$A R E A^{2}$ & Square of farmland area & $774.888 / 201.750$ & $7965.337 / 1586.421$ &,,--+ \\
\hline NOL & Number of labourers & $7.512 / 6.477$ & $6.469 / 4.457$ & + \\
\hline FAC & Whether funds have been accumulated & $0.692 / 0.658$ & $0.463 / 0.475$ & + \\
\hline$R M M F I$ & Ratio between a farmer's potential migrant money and his real farming income & $-/ 0.176$ & $-/ 0.102$ & - \\
\hline TER & Terrain & $2.635 / 2.611$ & $0.679 / 0.716$ & + \\
\hline$R E G$ & Region & $0.251 / 0.230$ & $0.435 / 0.421$ & + \\
\hline FMSS & Whether farm machinery or socialised services are bought & $0.678 / 0.607$ & $0.468 / 0.489$ & + \\
\hline $\operatorname{IRR}$ & Status of irrigation facilities & $0.801 / 0.786$ & $0.400 / 0.411$ & + \\
\hline
\end{tabular}

Notes: / Prior to the separator, /, is data of big grain production households, and following is that of the comprehensive family farms. ${ }^{\#}$ Three sign predictions exist for Eq. (3)-Eq. (5), respectively. ${ }^{\$}$ Only one sign prediction exists, which means the sign predictions in Eq. (3)-Eq. (5) are the same.

\section{Regression Results}

The regression analysis used the statistical software Stata 14. Because the dependent variables are all continuous random variables, the Method of Ordinary Least Squares (OLS) is used to estimate all regression models.

\subsection{The Estimated Optimal Land Management Scale of the Big Grain Production Household}

The estimated results of regression Eq. (3) are presented in Table 2, including GYPL and PCGY. The whole significance test statistics, $F \mathrm{~s}$, of both models are all significant at the significance level of $1 \%$, which shows that their regression results as a whole are good.

Grain yield per labour (GYPL) of the big grain production household is significantly influenced by farmland area $(A R E A)$ and its square $\left(A R E A^{2}\right)$, number of labourers $(N O L)$, terrain $(T E R)$, region $(R E G)$, whether farm machinery or socialised services are bought (FMSS), and status of irrigation facilities $(I R R)$, which display signs consistent with the predictions. Education years of the manager $(E D U)$ is not significant. Perhaps because China did not provide an education according to the different demands of the urban and rural economic society, education does not significantly affect the grain yield. Whether funds have been accumulated
$(F A C)$ is not significant either. The survey data gathered the information of the current status of accumulated funds of the manager, which will affect the grain yield in the future, while the present yield is influenced by the past accumulated funds, so FAC is not significant. The signs of $A R E A$ and $A R E A^{2}$ are positive and negative, respectively, which confirms the argument that as arable land increases, the grain yield per labour increases at a diminishing rate. To determinate the extreme point of the quadratic function curve, $G Y P L=\mathrm{f}(A R E A)$, except $A R E A$ and $A R E A^{2}$, the other explanatory variables that have significant influence on GYPL take their mean values, and the insignificant explanatory variables are omitted. According to Table 1 and Table 2, we obtain the following: $G Y P L=0.032 A R E A^{2}+$ $0.952 A R E A+16.671+1.756 * 7.512+0.278 * 2.635+8.48 * 0.251$ $+2.123 * 0.678+0.154 * 0.801=-0.032 A R E A^{2}+0.952 A R E A+34.2$ 86. Then, we use Eq. (1) and Eq. (2) to obtain the optimal land management scale of the big grain production households, $14.875 \mathrm{hm}^{2}$, and the maximum value of the grain yield per labour, 41.366 thousand $\mathrm{kg}$ /person-year, under present productivity levels. Table 1 shows that the real farmland size and the grain yield per labour of the big grain production households are $9.482 \mathrm{hm}^{2}$ and 17.185 thousand $\mathrm{kg} /$ person-year, respectively. Hence, for labour endowment, the big grain production households did not generally realize 
the optimal land management scale. If the land area continues to increase, the grain yield per labour has a large opportunity for growth, approximately 24.181 thousand $\mathrm{kg} /$ person-year.

To test the robustness of these results [21], per capita grain yield $(P C G Y)$ is regressed as well as seen in Table 2. Similarly, we obtain the quadratic function, $P C G Y=$ $-0.033 A R E A^{2}+0.867 A R E A+19.179$. When $A R E A=13.136$ $\mathrm{hm}^{2}, P C G Y$ reaches the maximum value, 24.874 thousand $\mathrm{kg} /$ person-year. Table 1 shows that the real farmland size and the per capita grain yield of the big grain production households are $9.482 \mathrm{hm}^{2}$ and 19.302 thousand $\mathrm{kg} /$ person-year, respectively. Hence, as a reference, the per capita grain yield model also confirms that the big grain production households did not realise the optimal land management scale.

Table 2. Regression results of Eq. (3) and Eq. (4).

\begin{tabular}{|c|c|c|c|c|}
\hline $\begin{array}{ll}\text { Exp. Vars. } & \text { Dep. Vars. }\end{array}$ & GYPL & PCGY & $A I P L$ & PCAI \\
\hline $\mathrm{C}$ & $16.671^{* * *}(6.198)^{\#}$ & $0.523(0.122)$ & $140.630^{* * *}(17.668)$ & $98.964^{* * *}(8.009)$ \\
\hline$A R E A$ & $0.952^{* * *}(28.660)$ & $0.867^{* * *}(14.835)$ & $0.959^{*}(1.820)$ & $1.688^{* *}(2.234)$ \\
\hline$A R E A^{2}$ & $-0.032^{* * *}(-18.872)$ & $-0.033^{* * *}(-9.180)$ & $-0.029^{*}(-1.829)$ & $-0.061^{*}(-1.886)$ \\
\hline$E D U$ & $-0.182(-0.985)$ & $0.659^{* *}(2.233)$ & $0.408(0.792)$ & $1.390^{*}(1.738)$ \\
\hline NOL & $1.756^{* * *}(18.111)$ & $0.621^{* * *}(4.009)$ & $5.783^{* * *}(12.355)$ & $2.700^{* * *}(3.717)$ \\
\hline$F A C$ & $0.251(0.870)$ & $1.679(1.235)$ & $1.113(1.296)$ & $5.020(0.888)$ \\
\hline$R M M F I$ & - & - & $-170.537^{* * *}(-11.537)$ & $-214.463^{* * *}(-9.346)$ \\
\hline TER & $0.278^{* * *}(3.347)$ & $1.327^{*}(1.784)$ & $1.346^{* *}(2.238)$ & $4.469^{* * *}(4.322)$ \\
\hline$R E G$ & $8.480^{* * *}(5.977)$ & $2.057^{*}(1.807)$ & $12.739^{* * *}(3.028)$ & $2.632^{*}(1.773)$ \\
\hline FMSS & $2.123^{* *}(2.236)$ & $2.391^{*}(1.798)$ & $0.133^{*}(1.746)$ & $3.452^{*}(1.796)$ \\
\hline $\operatorname{IRR}$ & $0.154^{*}(1.801)$ & $1.393^{* *}(2.227)$ & $4.205^{*}(1.790)$ & $3.358^{* * *}(3.520)$ \\
\hline Obs. & 211 & 211 & 257 & 257 \\
\hline$F($ Prob $>F)$ & $163.99^{* * *}(0.000)$ & $610.28^{* * *}(0.000)$ & $34.86^{* * *}(0.000)$ & $29.42^{* * *}(0.000)$ \\
\hline $\mathrm{R}^{2} / \overline{\mathrm{R}}^{2}$ & $0.880 / 0.875$ & $0.965 / 0.963$ & $0.686 / 0.669$ & $0.645 / 0.626$ \\
\hline Function $\$$ & $-0.032 X^{2}+0.952 X+34.286$ & $-0.033 X^{2}+0.867 X+19.179$ & $-0.029 X^{2}+0.959 X+157.902$ & $-0.061 X^{2}+1.688 X+111.783$ \\
\hline$X_{0} / Y_{0}$ & $14.875 / 41.366$ & $13.136 / 24.874$ & $16.534 / 165.831$ & $13.836 / 123.461$ \\
\hline
\end{tabular}

Notes: ${ }^{*}$ Prior to the parenthesis is the estimated coefficient and its $t$ value is in the parenthesis. ${ }^{*},{ }^{* *}$ and ${ }^{* * *}$ show the variables are statistically significant at the significance level of $10 \%, 5 \%$ and $1 \%$, respectively. ${ }^{\$}$ The variable, $X$, in the functional expression is $A R E A$.

\subsection{The Estimated Optimal Land Management Scale of the Comprehensive Family Farms}

For the estimated results of the regression Eq. (4) see Table 2, including $A I P L$ and PCAI. The whole significance test statistics, $F \mathrm{~s}$, of both models are all significant at the significance level of $1 \%$, which shows their regression results are good as a whole.

Agricultural income per labour $(A I P L)$ of the comprehensive family farms is significantly influenced by $A R E A, A R E A^{2}, N O L, R M M F I, T E R, R E G, F M S S$ and IRR, whose signs are consistent with the predictions. $E D U$ and $F A C$ are not significant (see previous discussion). The signs of $A R E A$ and $A R E A^{2}$ are positive and negative, respectively, which confirms the argument that with an arable land increase, the agricultural income per labour increases at a diminishing rate. Similar to the big grain production households, except $A R E A$ and $A R E A^{2}$, the other explanatory variables that have significant influence on $A I P L$ take their mean values, and the insignificant explanatory variables are omitted. Thus, we obtain $A I P L=-0.029 A R E A^{2}+0.959 A R E A$ +157.902. Further, we calculate the optimal land management scale of the comprehensive family farm, 16.534 $\mathrm{hm}^{2}$, and the maximum value of the agricultural income per labour, 165.831 thousand RMB/person-year, under present productivity levels, but the two real values are $6.295 \mathrm{hm}^{2}$ and 79.485 thousand RMB/person-year, respectively (see Table 1). Hence, for labour endowment, the comprehensive family farms did not generally realise the optimal land management scale. If farmland area continues to increase, agricultural income per labour will increase by approximately 86.346 thousand RMB/person-year.

To test the robustness of these results [21], per capita agricultural income (PCAI) is regressed as well (see Table 2). Similarly, we obtain PCAI=-0.029AREA ${ }^{2}+0.959 A R E A$ +157.902 . When $A R E A=16.534 \mathrm{hm}^{2}, P C A I$ reaches the maximum value, 165.831 thousand RMB/person-year. Table 1 shows that the real farmland size and the per capita agricultural income of the comprehensive family farms are $6.295 \mathrm{hm}^{2}$ and 89.412 thousand RMB/person-year, respectively. Hence, as a reference, the per capita agricultural income model also confirms that the comprehensive family farms did not realize the optimal land management scale.

\subsection{The Inverse Relationship Tested}

The grain yield per unit (GYPU) model, i.e., the regression Eq. (5), fits the surveyed data of the big grain production households, the comprehensive family farms, and their integration, respectively (see Table 3). The whole significance test statistics, $F$ s, of the three regressions, i.e., GYPU 1, GYPU 2 and GYPU 3, are all significant at the significance level of $1 \%$, which shows their regression results are good as a whole. The signs of all significant explanatory variables are consistent with the predictions. That the results of the model fit all three sets of data shows that the signs of $A R E A$ and $A R E A^{2}$ are negative and positive, respectively, consistent with the predictions. However, only $A R E A$ is significant, and $A R E A^{2}$ is insignificant, which is different 
from the results of $\mathrm{Ni}$ and $\mathrm{Cai}$ [21]. Hence, the argument that there is an inverse relationship between farm size and productivity, i.e., grain yield per unit, is confirmed. Grain yield per unit monotonously decreases with farm size rather than declines at a diminishing rate to a minimum and then increases [21]. In a word, the grain yield per unit does not have an extreme point. That is, from the land endowment perspective, an optimal land management scale for both the big grain production households and the comprehensive family farms does not exist. Similarly, except $A R E A$, the other explanatory variables that have significant influence on GYPU 1-GYPU 3 take their mean values, and the insignificant explanatory variables are omitted, and we obtain the function, GYPU=f(AREA) (see Table 3). Note that the mean values of the explanatory variables of the big grain production households (see Table 1) and that of the comprehensive family farms should be solved after leaving out the 37 farms that did not grow food (omitted).

Table 3. Regression results of Eq. (5).

\begin{tabular}{llll}
\hline Exp. Vars. & $\begin{array}{l}\text { GYPU 1 } \\
\text { (Big Grain Prod. Hous.) }\end{array}$ & $\begin{array}{l}\text { GYPU 2 } \\
\text { (Comp. Fam. Far.) }\end{array}$ & $\begin{array}{l}\text { GYPU 3 } \\
\text { (Int.) }\end{array}$ \\
\hline C & $15.913^{* * *}(22.213)^{*}$ & $21.503^{* * *}(17.924)$ & $17.972^{* * *}(22.368)$ \\
$A R E A$ & $-0.014^{* *}(-2.245)$ & $-0.122^{*}(-1.799)$ & $-0.023^{*}(-1.858)$ \\
$A R E A^{2}$ & $0.001(0.305)$ & $0.002(1.293)$ & $0.001(1.428)$ \\
$E D U$ & $-0.015(-0.298)$ & $0.017(0.224)$ & $0.033(0.626)$ \\
$N O L$ & $0.025^{*}(1.865)$ & $0.204^{* * *}(3.102)$ & $0.089^{* * *}(2.698)$ \\
$F A C$ & $0.925^{* *}(2.346)$ & $0.825^{*}(1.874)$ & $1.080^{* * *}(2.694)$ \\
$T E R$ & $0.339^{*}(1.886)$ & $0.400^{*}(1.878)$ & $0.250^{* *}(2.229)$ \\
$R E G$ & $0.254^{*}(1.772)$ & $0.153^{* * *}(2.623)$ & $1.211^{* * *}(3.006)$ \\
$F M S S$ & $0.128(0.322)$ & $1.934^{* * *}(3.421)$ & $1.219^{* * *}(2.981)$ \\
$I R R$ & $0.652^{*}(1.760)$ & $-0.627(-0.947)$ & $0.795^{*}(1.857)$ \\
Obs. & 211 & $220^{(9)}$ & 431 \\
$F($ Prob $>F)$ & $26.36^{* * *}(0.000)$ & $15.47^{* * *}(0.000)$ & $9.62^{* * *}(0.000)$ \\
$\mathrm{R}^{2} / \overline{\mathrm{R}}^{2}$ & $0.659 / 0.620$ & $0.599 / 0.567$ & $0.578 / 0.549$ \\
Functions $^{\mathrm{S}}$ & $-0.014 X+18.220$ & $-0.122 X+25.883$ & $-0.023 X+21.795$ \\
\hline
\end{tabular}

Notes: ${ }^{*}$ Prior to the parenthesis is the estimated coefficient and its $t$ value is in the parenthesis. ${ }^{*},{ }^{* *}$ and ${ }^{* * *}$ show the variables are statistically significant at the significance levels of $10 \%, 5 \%$ and $1 \%$, respectively. ${ }^{@}$ The comprehensive family farms still had 220 observations after leaving out the 37 farms that were not growing food from the 257 observations. ${ }^{\$}$ The variable, $X$, in the functional expression is $A R E A$.

\subsection{Decision Graph of Farmland Management Scale}

Above all, we can draw the decision graph of farmland management scale under current productivity levels (see Figure 1). It shows that the optimal land management scale of the big grain production households is from 13.1 to 14.9 $\mathrm{hm}^{2}$ and that of the comprehensive family farms is from 13.8 to $16.5 \mathrm{hm}^{2}$. There is an inverse relationship between land productivity, i.e., the grain yield per hectare, and arable land area for both the big grain production households and the comprehensive family farms. The land productivity is a monotonous decrease function rather than a quadratic function, without the possibility that it declines to a minimum and then increases.

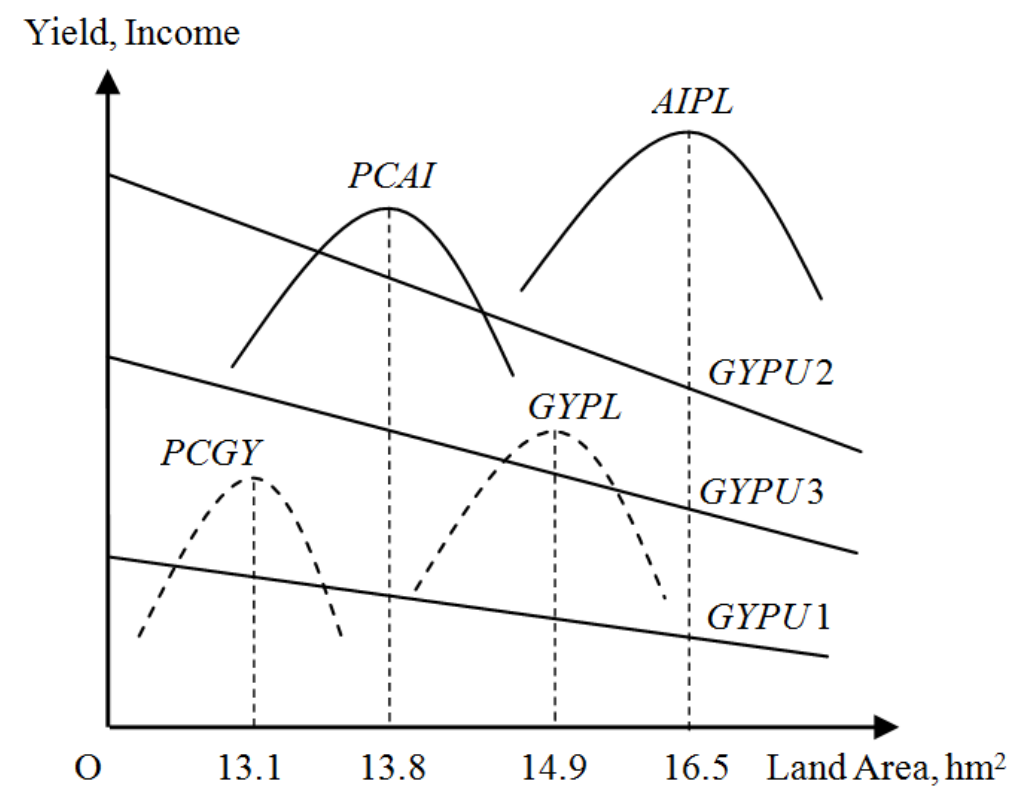

Figure 1. Decision graph of farmland management scale. 


\section{Conclusions and Implications}

Through the aforementioned analysis, we can reach the following important conclusions:

Firstly, the mean value of the real farmland size and that of the real grain yield per labour of the big grain production households are $9.482 \mathrm{hm}^{2}$ and 17.185 thousand $\mathrm{kg} /$ person-year, respectively. Under current productivity levels, for labour endowment, the optimal land management scale of the big grain production households is from 13.1 to $14.9 \mathrm{hm}^{2}$, and the extreme value of the grain yield per labour is from 24.9 to 41.4 thousand $\mathrm{kg}$ /person-year. Thus, both the farmland size and the labour productivity of the big grain production households have substantial room for growth.

Secondly, the mean value of the real farmland size and that of the real agricultural income per labour of the comprehensive family farms are $6.295 \mathrm{hm}^{2}$ and 79.485 thousand RMB/ person-year, respectively. Under current productivity levels for labour endowment, the optimal land management scale of the comprehensive family farms is from 13.8 to $16.5 \mathrm{hm}^{2}$, and the extreme value of the agricultural income per labour is from 123.5 to 165.8 thousand $\mathrm{RMB} /$ person-year. Thus, both the farmland size and the labour productivity of the comprehensive family farms have considerable room for growth.

Finally, there is a negative correlation between grain yield per unit and arable area, which confirms the inverse relationship. Meanwhile, the quadratic function relationship between the grain yield per unit and the arable area has been rejected. In other words, the grain yield per unit monotonously decreases, without the possibility that it declines to a minimum and then increases. Hence, to improve farmland productivity, the size should be decreased, which comes at the cost of decreased labour productivity.

The implications of these conclusions are as follows:

To realise the maximum utilization of labour endowment, it is necessary to accelerate farmland concentration from scattered farm households to big grain production households or comprehensive family farms. In land transfer, on the one hand, land managers should avoid high rent; on the other hand, the re-employment question of land-lost farmers should be settled properly. These problems may be solved by transferring land at lower prices and land-lost farmers working in the scale farms and participating in the profit of land production. This would ensure that the land managers not only obtain economies of scale at a lower cost but also mobilize the motivation of hired labourers, which solves the problem of ineffective employment.

In the context of China's low agricultural comparative benefits and rising labour costs, to promote farmland productivity, decreasing the farmland size is inappropriate because it will come at the cost of diminishing returns to scale. With a decrease in farmland size, labour productivity declines, which results in a decrease in farmers' income and an increase in rural labourers leaving agriculture. Agriculture may lose the motivation of sustainable development.

\section{Acknowledgements}

This research was supported by 2017 Soft Science Research of Technical Innovation Project of Hubei Province, China, Project Number: 2017ADC082 and 2017ADC083.

\section{References}

[1] R. Li, Y. Chao, "Study on the determinants of the revenue of a big grain production household and moderate planting scale," Rural Economy, 2014, (2), pp. 27-30. (in Chinese).

[2] Y.-j. Zheng, "Analysis on the land moderate scale management of a family farm," Land \& Resources Herald, 2013, (7), pp. 21-23. (in Chinese).

[3] J.-y. Jiang, S.-y. Zhang, B.-w. Li, et al., "Does blindness exist in the farmers' intention to expand farmland scale?" China Population, Resources and Environment, 2016, 26(8), pp. 97-104. (in Chinese).

[4] T. Lefroy, J. Key, and R. Kingwell, "An examination of Broadacre farm size and performance in Western Australia," Australian Economic Review, 2017, 50(1), pp. 52-65.

[5] B. T. Anang, S. Backman, and A. Rezitis, "Does farm size matter? Investigating scale efficiency of peasant rice farmers in Northern Ghana," Economics Bulletin, 2016, 36, (4), pp. 2275-2290.

[6] L. Liang, S.-1. Lin, and Z.-x. Zhang, "Effect of the family life cycle on the family farm scale in Southern China," Agricultural Economics, 2015, 61(9), pp. 429-440.

[7] M. Kołtun, S. Kocira, Z. Krzysiak, et al, "Economic size and developmental possibilities of chosen family farms in Poland," Agriculture and Agricultural Science Procedia, 2015, 7, pp. 113-118.

[8] S. K. Lowder, J. Skoet, and T. Raney, "The number, size, and distribution of farms, smallholder farms, and family farms Worldwide," World Development, 2016, 87, pp. 16-29.

[9] Y.-g. Wu, "Moderate scale management of family farm in Guangxi," Journal of Southern Agriculture, 2014, 45(4), pp. 709-714. (in Chinese).

[10] W.-r. Lu, Y. Duan, and H.-1. Lu, "Family farm: Based on the business practice with an appropriate scale within the village," China Agricultural University Journal of Social Sciences Edition, 2014, 31(3), pp. 95-105. (in Chinese).

[11] X.-k. Zhang, "Development advantages of large-scale family farm," Modern Agricultural Science and Technology, 2013, (9), pp. 321-325. (in Chinese).

[12] K.-m. Qian and T.-j. Peng, "Economic analysis of the moderate scale farmers in food production," Issues in Agricultural Economy, 2014, (3), pp. 4-7. (in Chinese).

[13] E. Blanc, A. Lepine, and E. Strobl, "Determinants of crop yield and profit of family farms: Evidence from the Senegal River valley," Experimental Agriculture, 2016, 52(1), pp. 110-136. 
[14] Y. Sheng, S.-j. Zhao, K. Nossal, et al, "Productivity and farm size in Australian agriculture: Reinvestigating the returns to scale," Australian Journal of Agricultural and Resource Economics, 2015, 59(1), pp. 16-38.

[15] S. Gaurav and S. Mishra, "Farm size and returns to cultivation in India: Revisiting an old debate," Oxford Development Studies, 2015, 43(2), pp. 165-193.

[16] L. Cielava, D. Jonkus, and L. Paura, "Effect of farm size on the productivity and longevity of Latvian Brown cows," 20th Annual International Scientific Conference on Research for Rural Development, Latvia Univ Agr, Jelgava, 2014.

[17] C. Carletto, S. Savastano, and A. Zezza, "Fact or artifact: The impact of measurement errors on the farm size-productivity relationship," Journal of Development Economics, 2013, 103, pp. 254-261.

[18] H. Henderson, "Considering technical and allocative efficiency in the inverse farm size-productivity relationship," Journal of Agricultural Economics, 2015, 66(2), pp. 442-469.

[19] D. A. Ali and K. Deininger, "Is there a farm size-productivity relationship in African agriculture? Evidence from Rwanda," Land Economics, 2015, 91(2), pp. 317-343.

[20] J.-y. Wang, K. Z. Chen, S. Das Gupta, et al, "Is small still beautiful? A comparative study of rice farm size and productivity in China and India," China Agricultural Economic Review, 2015, 7(3), pp. 484-509.
[21] G.-h. Ni and F. Cai, "What is the proper land management scale really needed by farmers?" Economic Research Journal, 2015, (3), pp. 159-171. (in Chinese).

[22] X.-n. Ren, G.-q. Meng, C. Li, et al., "Large-scale land management and influencing factors of large-scale grain-production households," Journal of Hunan Agricultural University (Social Sciences), 2015, 16(2), pp. 12-17. (in Chinese).

[23] H. Yuan and J.-z. Gao, "Lower limit of family farms' land scale based on propensity score matching," Guizhou Agricultural Science, 2015, 43(3), pp. 198-201. (in Chinese).

[24] Y. Sheng, A. Davidson, K. Fuglie, et al, "Input substitution, productivity performance and farm size," Australian Journal of Agricultural and Resource Economics, 2016, 60(3), pp. 327-347.

[25] B. Zhou, "Empirical analysis on the optimization problem of rice planted area of a big grain production household," Journal of Agrotechnical Economics, 2010, (4), pp. 120-127. (in Chinese).

[26] S. Panda, "Farmer education and household agricultural income in rural India," International Journal of Social Economics, 2015, 42(6), pp. 514-529.

[27] Y. Liu and J.-k. Huang, "A multi-objective decision model of farmers' crop production," Economic Research Journal, 2010, (1), pp. 148-157. (in Chinese). 